\title{
Energy Scheduling for Island Microgrid Applications
}

\author{
Galia Marinova ${ }^{1}$ and Vassil Guliashki ${ }^{2}$ \\ 1. Faculty of Telecommunications at Technical University of Sofia, Sofia 1000, Bulgaria \\ 2. Institute of Information and Communication Technologies - BAS, Sofia 1113, Bulgaria
}

\begin{abstract}
The paper considers the calculation of an effective energy schedule in an islanded microgrid. GridLab-D open source simulation tool is used for simulation of microgrid elements. Matlab environment is used to run an optimization solver. The product GridMat is used as an interface tool between Matlab and GridLab-D. An economic scheduling optimization problem for the considered microgrid is formulated and solved. Analysis of the obtained results is presented.
\end{abstract}

Key words: Microgrids, GridLab-D, GridMat, Matlab, energy scheduling optimization.

\section{Introduction}

A microgrid is a low-voltage distribution system, integrating DERs (distributed energy resources) or RES (renewable energy sources) and controllable loads, which can be used/controlled in either islanded or grid-connected mode [1]. In the first case the microgrid is disconnected from the main grid and it needs to integrate an IPP (independent power producer), for example a diesel generator. In the second case the microgrid is connected to the main grid (the Network) which allows to share the power generation through buying or selling energy.

DERs/RES may include for example energy storages/batteries, solar/photovoltaic panels, micro hydro, wind turbines, etc. The distributed/renewable energy resources (generators) and storage systems make the microgrid more secure and reliable, for instance, in case of disasters such as earthquake, which might cause a lengthy power outage in electrical power grid. On the other hand, the microgrid should be robust in controlling supply, demand, voltage and frequency [2].

The DERs/RES production plan can be estimated by using meteorological forecasts, which have an

Corresponding author: Galia Marinova, Ph.D., associate professor, research fields: modeling, simulation and computer-aided design in communications, statistical analysis and design. intrinsic uncertainty. In such a setup, adding energy storage gives flexibility to the energy system [3]. The timely produced satellite meteorological forecasts can ensure enough time for specialists in the area to formulate and to solve corresponding optimization tasks. The optimal battery schedule may lead to minimal energy consumption from the main grid and to reduced environment impact/pollution (for example minimizing the exploitation of diesel generators).

This paper is an extended version of Ref. [4]. Here the microgrid economic scheduling is studied, i.e. the problem to optimize the energy storage/battery schedule, as well as the schedule of the diesel generator used, covering the time-varying energy demand and operational constraints while minimizing the costs of internal generated energy.

The experimental setup consists in a simple microgrid, including photovoltaic system, wind turbine, diesel generator and three houses. In this study the microgrid's PCC (point of common coupling) is disconnected from the main grid and the microgrid operates in an island mode. When formulating an optimization task the amount of power demand and the supply for the next 24 hours period are presumed to be known and without any change. This is an unrealistic setup, especially in real world applications. For example, there could appear great fluctuations in the wind generators output. The solar radiation 
forecasts could also be inexact and could vary essentially. For this reason the energy, generated by the diesel generator should include a reserve rate (see Refs. [5, 6]) and the forecasted data for each microgrid element - for the renewable energy resources (wind turbine and photovoltaic system), and a safe margin should be added for the loads (houses). The optimized safe margins values obtained in Ref. [5] for a similar microgrid are used here, in the formulation of a realistic optimization problem.

The open source GridLab-D (see Ref. [7]) is used to simulate all the elements of the microgrid. The software product GridMat (see Refs. [2, 8]) is used as an interface tool between Matlab (see Ref. [9]) and GridLab-D. Climate data, available on the official website of GridLab-D, are used for the simulations. The optimization problem is formulated and solved in an efficient way by using the Matlab optimization toolboxes/solvers.

The paper is organized as follows: Section 2 considers the microgrid structure; Section 3 devotes to the simulation and optimization tools used in this study; Section 4 presents the optimization model for the economic energy scheduling; Section 5 presents the results obtained, from the simulation and the optimization; Some conclusions are drawn in Section 6.

\section{The Experimental Microgrid}

The microgrid studied in this work, is composed by several units which produce, exchange and consume energy. Essentially, the microgrid operates with a three-phase medium voltage AC (alternating current) transmission system, which can be connected or not, to the main grid (Network) through a transformer system, in order to buy the energy necessary to cover the demand, or sell the surplus energy produced by the RES. When the microgrid is used in an Island mode (disconnected from the Network), a diesel generator is considered in order to supply, together with the RES, the energy necessary to cover the loads. Two types of RES are considered connected in the Microgrid: 1) a photovoltaic system, composed by an inverter and a group of solar panels, and 2) a wind turbine. A group of batteries (energy storage system) is also interconnected to the microgrid through a DC/AC bi-directional inverter: these batteries can modify their own schedule of charge/discharge in order to meet the needs of the microgrid. This special part makes the microgrid under study a smart microgrid, since the schedule of batteries is based on the behavior of the loads and the energy production by the RES. The system configuration of the proposed microgrid is presented on Fig. 1.

Simulations performed and the formulated optimization task are considered only for a microgrid operating in Island (isolated) mode. Thus a diesel generator is included in the microgrid.

The components composing the microgrid are:

- Houses. Some parameters have been fixed, such as the floor area, cooling and heating systems and their set-points. The GridLab-D simulation tool, used in this study has the advantage to have default values for the systems used in the houses simulation; therefore,

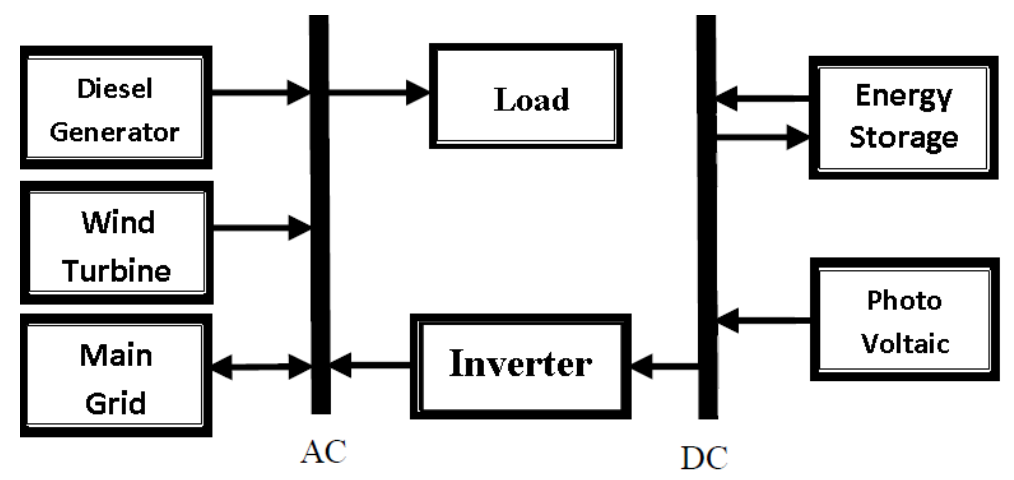

Fig. 1 Microgrid system configuration. 
for all parameters, which are not explicitly defined, the default value is used. Here is used a group of three houses, each connected to one phase of the transmission system; this approach is used in order to reduce the imbalance of the load between the phases of the microgrid.

- Photovoltaic. The photovoltaic power system is composed by solar panels and inverter (for connecting the system to the AC network with the loads). The parameter which has the greatest impact on the power production is the area of the whole photovoltaic system. In the concrete case, the area of all solar panels is set to $1,500 \mathrm{ft}^{2}$. This value corresponds to a produced power with peak around $25-30 \mathrm{~kW}$ (the value is obtained from the simulations).

- Wind turbine. A specific model of the wind turbine is used here: "Bergey $10 \mathrm{~kW}$ '. By means of command "Turbine Model" in the GridLab-D code, and specifying the concrete wind turbine model, the turbine parameters upload automatically their default values.

- Battery. For the simulations the battery block (batteries $+\mathrm{AC} / \mathrm{DC}$ inverter) is considered as not connected to the microgrid, since the behavior of the battery system is unknown and the battery schedule should be calculated by a Matlab solver to solve the correspondent optimization task. The battery system is composed by a battery block (with maximum energy storable of $100 \mathrm{kWh}$ ) and an inverter for the charge/discharge of the battery (with maximum power of $10 \mathrm{~kW})$.

- Diesel generator. Here is used a $35 \mathrm{kw} / 44 \mathrm{kVA}$ KOHLER Systems diesel generator (engine type: 3029TF120, class G3). This diesel generator has a rated power of $38 \mathrm{~kW}$ and a rated voltage of $400 / 230$ V (see http://www.kohlerpower.com.sg/industrial/ detail.htm?sectionNumber $=13261 \&$ categoryNumber= 11961\&prodnum=248461).

The experimental microgrid used is shown in Fig. 2.

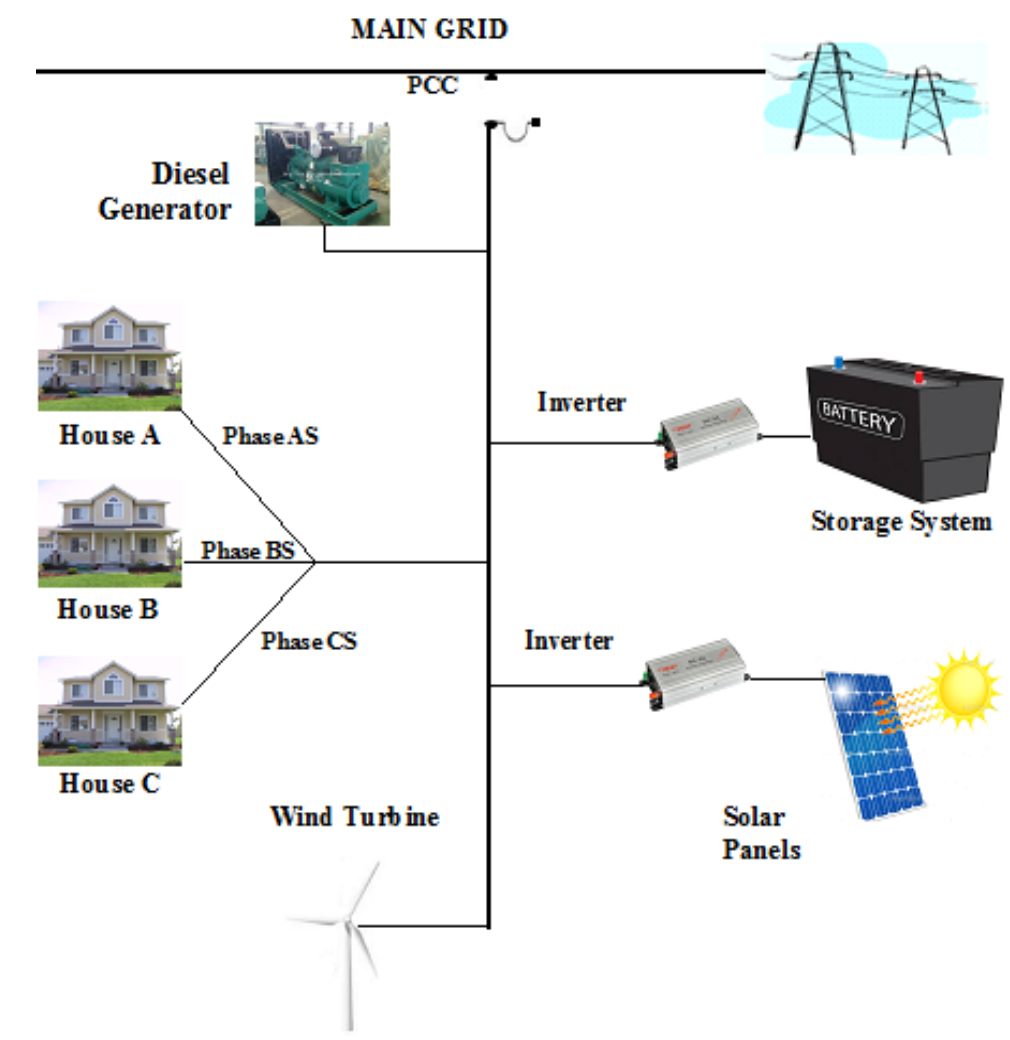

Fig. 2 The experimental microgrid. 


\section{Simulation and Optimization Tools}

\subsection{MATLAB Environment for Microgrid's Analysis}

In this study the solver "fmincon" from "Optimization Toolbox" in the software environment MATLAB is used.

\subsection{Simulation Tool GridLab-D}

Modeling complex, large-scale, heterogeneous, multiphysics, multi-domain, and distributed system, such as a microgrid, requires heterogeneous composition of physical, computational and communication sub-systems [8, 10]. Simulation tool, corresponding to these needs, is GridLab-D. It was developed by the U.S. DOE (Department of Energy) at PNNL (Pacific Northwest National Laboratory) under funding for Office of Electricity in collaboration with industry and academia [7] and it is a sponsored open-source, multi-domain modeling (power, weather, market) and simulation (it uses discrete event-based model of computation) tool for power systems (particularly suitable for distribution grid). GridLab-D incorporates the most advanced modeling techniques, with high-performance algorithms to deliver the best in end-use modeling. For the above reasons this tool is used here.

\subsection{The Tool GridMat}

GridLab-D is limited in supporting advanced control algorithm development and does not provide a user friendly interface for modeling the structural and behavioral aspects of a residential Microgrid. Therefore, a new Matlab toolbox is created (see Ref. [8]) to integrate the capabilities of domain-specific modeling and simulation tools for power system (GridLab-D) and control (Matlab). The new toolbox, called GridMat, is an open-source tool, used for academic and research activities. This tool supports user friendly model creation, robust debugging, and intelligent grid impact analysis utilities [8, 11]. It can be used to facilitate the control engineers in developing advanced and hierarchical control algorithms for a residential microgrid. For these reasons it is used here.

\section{Economic Scheduling Optimization Model}

In this study the behavior of the RES and houses has been simulated from historical climate data of a particular geographical position: Seattle (USA); the data for solar radiation and wind speed, as well for the houses energy consumption are real data for a given winter day. They are taken as forecasted data.

The experimental results in Ref. [5] about the energy safety margins, used to cover the uncertainty of the forecasted data are presented in Table 1 as follows.

Taking into account these margin values, the following values are assumed in the defined optimization model: Wind turbine: $(-30 \%)$; Photovoltaic: (-37\%); Houses: (+25\%); Diesel generator: $(+20 \%)$. This means that (the energy produced by the diesel generator + the energy of battery discharge) should be equal to $120 \%$ of the energy necessary to cover the difference between the $125 \%$ of (houses forecast + energy of battery charge) and $(70 \%$ of wind forecast $+63 \%$ of solar forecast), in order to cover the energy fluctuations due to forecast uncertainty, which could eventually arise. Having available correct forecasted data for the RES production and houses consumption a day before, it will be possible to optimize the microgrid behavior for the whole year, solving one day ahead the correspondent next day scheduling optimization problem.

The time interval being analysed (one day and one night) is divided by 24 time steps, each with 1 hour length. Formulated optimization problem has the form:

Table 1 Safety margin combination.

\begin{tabular}{lllll}
\hline Margins [\%] & Wind turbine margin & Photovoltaic margin & Demand margin & Reserve margin \\
\hline Obtained by trial and error & 30.2 & 36.6 & 25.5 & 20.0 \\
\hline
\end{tabular}


The balance power $P_{B}$ of the studied microgrid should satisfy the following equations (see Ref. [6]):

$$
\begin{aligned}
& P_{R E S}+P_{B}=P_{L} \\
& P_{B}=P_{\text {Bat } d}+P_{D G}
\end{aligned}
$$

where $P_{R E S}$ is the output power of renewable energy sources, $P_{B}$ is the balance power, $P_{B a t d}$ is the power from discharging the battery system, $P_{D G}$ is the output of the diesel generator, and $P_{L}$ is the microgrid load, equal to houses consumption energy plus battery system charging energy.

The parameters and the decision variables used in the proposed formulation are presented in Table 2.

The objective function, which has to be minimized, consists of the cost of microgrid balance power.

Objective function:

$$
\begin{aligned}
F & =\sum_{t=1}^{24}\left(C_{t} \cdot P_{B t}\right)=\sum_{t=1}^{24} C C_{D G}(t)+O M_{D G}(t)+F C_{D G}(t)+ \\
& +E C_{D G}(t)+\sum_{t=1}^{24} O M_{B a t}(t)+R C_{B a t}(t)+C C_{I n v}(t)
\end{aligned}
$$

where $P_{B t}$ is the balance power for hour $\mathrm{t}$ and $C_{t}$ is the cost of this power. In $C_{t}$ are included the deprecations costs of each microgrid energy generation element (unit), of individual units' operational costs, of the fuel cost (for the fuel consumed by the diesel generator), and of emission cost. It should be taken into account that the photovoltaic area, the wind turbine capacity, as well as the house energy consumption, cannot be subject to optimization since their schedules are independent. $F$ is calculated only for the hours, when the diesel generator operates and when the battery system is charging/discharging. In Refs. [12, 13] formulas for calculating the correspondent annual values are given. Hence, the hourly capital cost of microgrid units, which do not need a replacement during the project life time, such as diesel generator and inverter, is calculated as follows:

$$
C C_{D G}=\frac{C_{D G} \cdot \operatorname{CRF}(i, \mathrm{y})}{5375}
$$

Assuming, that the diesel generator is used in average 15 hours per $24 \mathrm{~h}$ period, the denominator is:
$5,375=15 \times 365$

$$
\operatorname{CRF}(i, \mathrm{y})=\frac{i \cdot(1+i)^{\mathrm{y}}}{(1+i)^{\mathrm{y}}-1}
$$

where, $\operatorname{Ccap}_{D G}$ is the capital cost (US\$), $\mathrm{y}$ is the project life time, and $i$ is the annual interest rate.

The annual interest rate is calculated as follows [14]:

$$
i=\frac{i^{\prime}-f}{1+f}
$$

where: $i$ ' is the loan interest (\%), and $f$ is the annual inflation rate $(\%)$.

The operation maintenance cost per hour is:

$$
O M=\frac{\operatorname{Ccap}_{D G} \cdot(1-\lambda)}{5375 . \mathrm{y}}
$$

for the diesel generator, and

$$
O M=\frac{\operatorname{Ccap}_{B a t} \cdot(1-\lambda)}{6570 . \mathrm{y}}
$$

for the battery, where: $\lambda$ is the reliability of the correspondent unit.

Assuming, that the battery bank is used in average for 18 hours per $24 \mathrm{~h}$ period (i.e. $365 \times 18=6,570$ hours annually), one hour battery bank replacement cost is:

$$
R C=\frac{\operatorname{Crep}_{\text {Bat }} \cdot \operatorname{SFF}\left(i, y_{\text {rep }}\right)}{6570}
$$

where: Crep is the replacement cost of battery bank, and SFF is the sinking fund factor, which is calculated as follows [14]:

$$
\mathrm{SFF}=\frac{i}{(1+i)^{\mathrm{y}}-1}
$$

The fuel cost of diesel generator per hour for the hour $t$ is:

$$
F C=C f \cdot G(t)
$$

Table 2 Parameters.

\begin{tabular}{ll}
\hline Parameter & Description \\
\hline CC & Capital cost for interval of 1 hour \\
OM & Operation maintenance for 1 hour \\
RC & Replacement cost (of the battery) \\
FC & Fuel cost for interval of 1 hour \\
EC & Emission cost for interval of 1 hour \\
CRF & Capital recovery factor for 1 hour \\
SFF & Sinking fund factor for 1 hour \\
\hline
\end{tabular}


where: $C f$ is the fuel cost per liter, and $G(t)$ is the hourly consumption of diesel generator. $G(t)$ is calculated in Refs. $[12,13,15,16]$ as follows:

$$
G(t)=\left(0.246 P_{D G}(t)+0.08415 . P_{R}\right)
$$

where: $P_{D G}(t)$ is the diesel power at time $t$, and $P_{R}$ is the rated power of the diesel generator.

The hourly emission cost $\left(\mathrm{CO}_{2}\right.$ emission) is:

$$
E C(t)=\frac{E_{f} \cdot E_{c f} \cdot P_{D G}(t)}{1000}=0,0187 \cdot P_{D G}(t)
$$

where: $E_{f}$ is the emission function $(\mathrm{kg} / \mathrm{kWh})$, and $E_{c f}$ is the emission cost factor ( $\$ /$ ton).

The economic data are given in Table 3.

Other parameters to be defined are the Pbt_max, fixed to $10 \mathrm{~kW}$ for charging and discharging, and $E_{b t \max }$, fixed to $100 \mathrm{kWh}$. The data in Table 3 are taken from Ref. [12], only the fuel cost value is taken from Ref. [13]. Since $P_{R}=38$, hence Ccap $_{D G}=19,000$ \$. In Ref. [6] is stated, that the high speed $(3,600$ $\mathrm{r} / \mathrm{min}$ ), air-cooled diesel can be used for about 20,000 h. Hence y in Eqs. (5), (7) and (8) is: $\mathrm{y}=3.721$. The annual interest rate $i=0.53846154$. Hence $\operatorname{CRF}(i, \mathrm{y})=$ 0.6742. $C C_{D G}=2.38 \$ / \mathrm{h} . O M_{D G}=0.095 \$ / \mathrm{h} . O M_{B a t}=$ $0.0061 \$ /$ h. Crep $_{B a t}=20,000 \$ . \mathrm{SFF}=0.1357 . \mathrm{RC}=$ $0.413 \$ / \mathrm{h}$. Ccap Inv $_{\text {In }}=10,000$. The inverter hourly capital cost is: $C C_{I n v}=1 \$ / \mathrm{h}$.

Hence, the objective Eq. (3) is presented in the form:

$$
\begin{aligned}
F= & \sum_{t=1}^{24} 2,38_{D G}(t)+0,095_{D G}(t)+0,1845 \cdot P_{D G}(t)+2,398_{D G}(t)+ \\
& +0,0187 . P_{D G}(t)+\sum_{t=1}^{24} 0,274_{B a t}(t)+0,413_{B a t}(t)+1_{l n v}(t)
\end{aligned}
$$

\section{Constraints:}

The constraints concerning the diesel generator are [17]:

$$
\text { 0.3. } P_{R} \leq P_{D G}(t) \leq P_{R}
$$

Taking into account the modified values from Table 1, the following constraint is obtained:

$$
P_{D G}(t)=\left\{\begin{array}{r}
1,2 \cdot\left(1,25 \cdot P_{L}-0,63 \cdot P_{P V}-0,7 \cdot P_{W T}-P_{B a t_{-} d}\right) \\
\text { if } 0,63 \cdot P_{P V}+0,7 . P_{W T}+P_{B a t_{-} d}<1,25 \cdot P_{L} \\
0 .
\end{array}\right.
$$

The constraints for the battery system are:

$$
\begin{gathered}
-P_{B T_{-} M A X} \leq P_{\mathrm{BAT}_{1}(T) \leq+P_{B T_{-} M A X}} \\
S O C_{M I N} \leq S O C(I) \leq S O C_{M A X} \\
\sum_{t=1}^{24} P_{\text {Bat }}(t)=0 ; \quad t=1, \ldots, 24 ;
\end{gathered}
$$

where: $P_{L}(t)$ is the power absorbed by the houses during the hour " $t$ " $[\mathrm{kW}] ; P_{P V}(t)$ is the power delivered by photovoltaic panels during the hour " $t$ " $[\mathrm{kW}] ; P_{W T}(i)$ is the power delivered by wind turbine during the hour " $t$ " $[\mathrm{kW}] ; P_{\text {Bat_d }}(t)$ is the power delivered by the battery block (discharging) during the hour " $t$ " [kW]. Pbt_max is the maximum power that the battery system can deliver/absorb [kW]; $S O C(t)$ is the State Of Charge of the battery during the hour " $t$ " [\%] $S O C_{\min }=$ lower limit for the State Of Charge of the battery [\%] $S O C_{\max }=$ upper limit for the State Of Charge of the battery [\%].

Finally, taking into account the energy balance of the microgrid (see Eqs. (1) and (2)), the last constraint obtained is:

$$
P_{B a t}(t)+P_{D G}(\mathrm{t}) \geq P_{H}(t)-P_{P V}(t)-P_{W T}(t), t=1, \ldots, 24 \text { (19) }
$$

where $P_{H}(t)$ is the house consumption energy. The energy $P_{B a t}(\mathrm{t})$ is considered positive when the battery is discharging and negative when is charging. Therefore, Eq. (16) represents the power limit, which can be delivered or absorbed by the inverter tie to the battery system; the system cannot supply or absorb a power more than the Pbt_max.

The SOC of the battery represents the amount of energy stored in the battery system. Therefore, Eq. (17) means that, for each time step, the SOC must be

Table 3 The economic data.

\begin{tabular}{ll}
\hline Description & Value \\
\hline Interest rate $i$ ' (\%) & 3 \\
Inflation rate (\%) & 1.6 \\
Inverter life time (years) & 20 \\
Battery life time (years) & 10 \\
Reliability of inverter (\%) & 0.98 \\
Reliability of battery (\%) & 0.98 \\
Reliability of diesel (\%) & 0.9 \\
Cost of diesel generator (US\$/KW) & 500 \\
Cost of battery bank (US\$/KWh) & 200 \\
Cost of inverter (US\$/KW) & 1000 \\
Fuel cost $(C f)(\mathrm{US} \$ / 1)$ & 0.75 \\
Emission function (kg/kWh) & 0.34 \\
Emission cost factor (US\$/ton) & 55 \\
\hline
\end{tabular}


included between a minimum and a maximum value, depending by the system used to store the energy and agrees with the physical limit of maximum SOC of $100 \%$. In this case, the minimum and maximum levels of SOC are fixed to $20 \%$ and $100 \%$ respectively.

The SOC is depending on the value of $P_{B a t}(\mathrm{t})$ for each time step; the relation between these variables is shown below [18]:

$$
\operatorname{SOC}(t)=\operatorname{SOC}(t-1)-\frac{P_{B a t}(t)}{E_{b t_{-} \max }} \cdot \Delta t
$$

where: $\Delta t$ is the time step [h], $\operatorname{SOC}(0)=$ Initial charge of the battery (it is an input value of the problem). In this optimization problem, the initial value of the SOC is fixed to $50 \%$. It means that, at the optimization start, the battery system is charged to the half of its full charge.

The constraint, shown in Eq. (18), is used in order to get, at the end of the $24 \mathrm{~h}$ period, the same value of SOC like at the begin of the period. Therefore, this value can be used as an input for the optimization task of the next day.

\section{Test Results Obtained by Means of Simulation and Optimization Tools}

\subsection{Simulation Results}

The simulations with GridLab-D give the results for the consumption of the houses, the production of the solar panels and wind turbine and the power flow from the diesel generator (in this case the battery system is not presented there). The results obtained from the simulations in a winter day, are shown on Fig. 3.

For simulation purposes, the user can upload the climate data of a particular zone or city, given from an external file with extension ".TMY2", where TMY is the acronym of "Typical meteorological year". In this study data are taken for one winter day for the city Seattle (USA)—see HTTPS://SOURCEFORGE.NET/P/ gridlab-d/code/4252/tree/course/ThreeDayCourse_v22 /Day2/Demos/4.4\%20Generator\%20Examples/. They correspond to the real data but here they are considered as forecasted data.

The graphics of houses consumption energy, photovoltaic produced energy and wind generated energy are presented on Fig. 4.

\subsection{Optimization Results}

Eqs. (13)-(19) have 48 variables: $P_{D G}(t)$ and $P_{B a t}(t)$, $t=1, \ldots, 24$; to solve this optimization problem, the Matlab solver FMINCON has been used. In the "HELP" menu in Matlab, in the "Optimization Toolbox" the

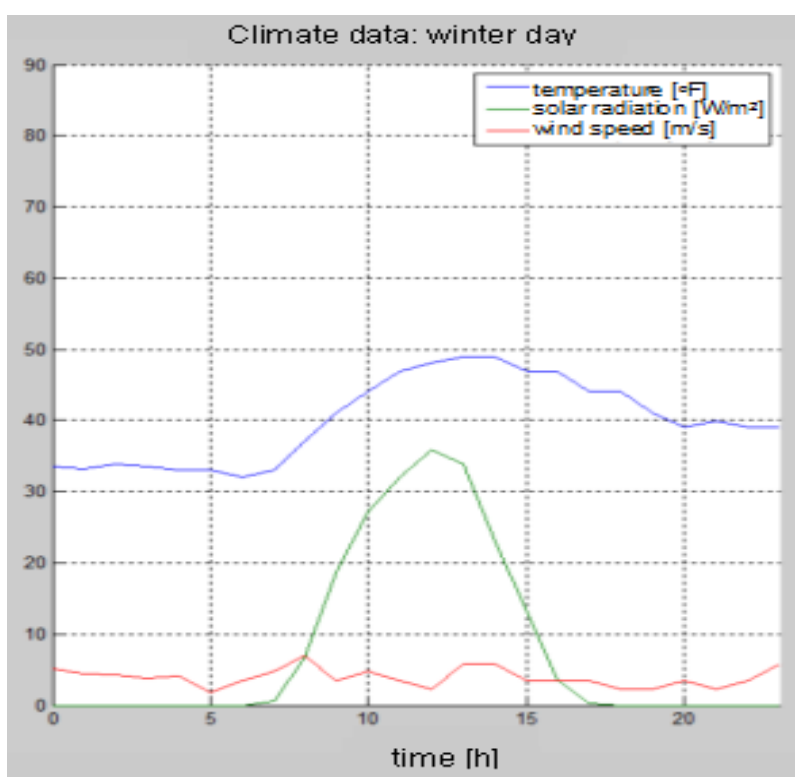

Fig. 3 Climate data trend (temperature, solar radiation and wind speed) in a winter day.

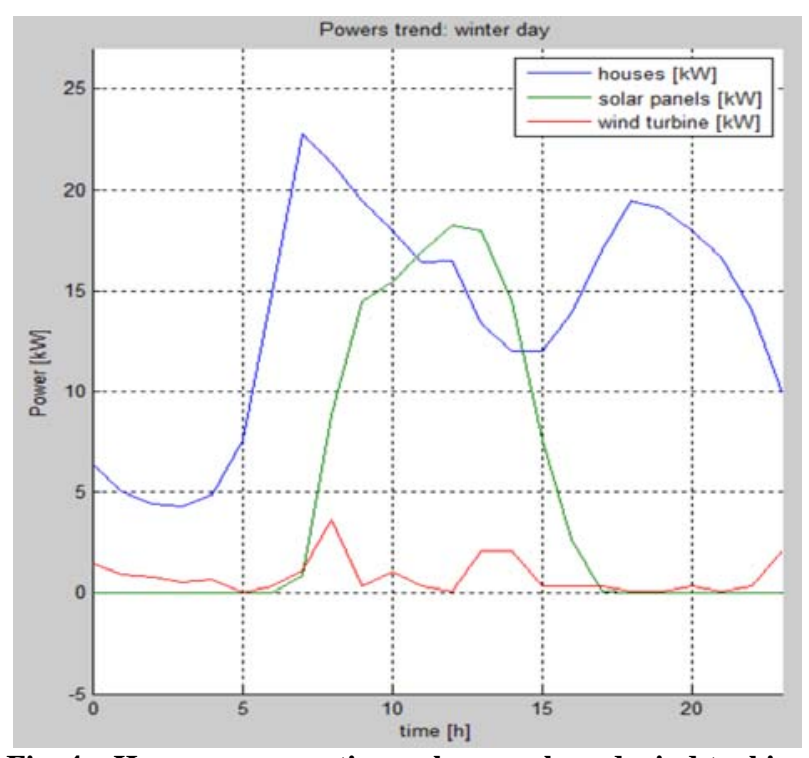

Fig. 4 Houses consumption, solar panels and wind turbine energy generation in a winter day. 
description and explanation how to run it is given.

fmincon: It finds the minimum of constrained nonlinear multivariable problem, it accepts a vector $\mathrm{x}$ for input and returns a scalar $f$ at output.

This solver can use several algorithms to optimize the problem, such as interior point, active set etc. In this case, it has been used the Active set algorithm.

After 18 iterations the optimal value of objective Eq. (13), which represents the costs for the diesel generator and the battery system (including the inverter) in [US\$] is: $F^{*}=205.037$.

The results of running "FMINCON" for a winter day using the "optimtool" command in Matlab are shown on Fig. 5.

\subsection{Analysis of Optimization Results}

The first 24 variables on Fig. 5 represent the battery schedule, and the next 24 variables correspond to the diesel generator schedule.

The calculated optimal schedule for the battery system is:

[-10. -10. -100 1.3786 10. -10. - -1.1083 10. 10. -10. -10. -10. 9.7297 -10. -10. 10. 10. 10. 10. -10. 10. 10.
10. -10.]

The calculated optimal schedule for the diesel generator is:

[11.4 11.4 11.4 11.4 0. 11.422 .016932 .5701

22.306517 .906214 .409611 .55440 .11 .411 .4

0. 18.471425 .138129 .121428 .580326 .6152

24.931020 .7732 13.0999].

The correspondent energy graphics are presented on Fig. 6.

The optimization result shows, that the total cost for $24 \mathrm{~h}$ period for a winter day, based on the objective Eq. (13) is: $F=205.037$. Without optimization for an initial battery schedule: $P_{B a t}\left(\begin{array}{l}0 \\ 0\end{array}=\left[\begin{array}{llllll}0 & 0 & 0 & -0.8 & -0.8 & -0.8\end{array}\right.\right.$ $\left.\begin{array}{llllllllllllllllllllll}-0.8 & -0.8 & -1 & 0 & 1 & 1 & 1 & 1 & 1 & -0.8 & -0.8 & -0.8 & -0.8 & -0.8 & -1 & 1 & 2 & 2\end{array}\right]$ the objective function value is $F=226.717$. Hence, the simultaneous optimization of battery schedule and diesel generator schedule leads to about $10.574 \%$ reduction of the costs.

The safety margins in the presented optimization model are necessary to cover the uncertainty of the data in the meteorological forecast, as well as in the data for the load (houses consumption). The graphics of the load (houses consumption) energy and the sum

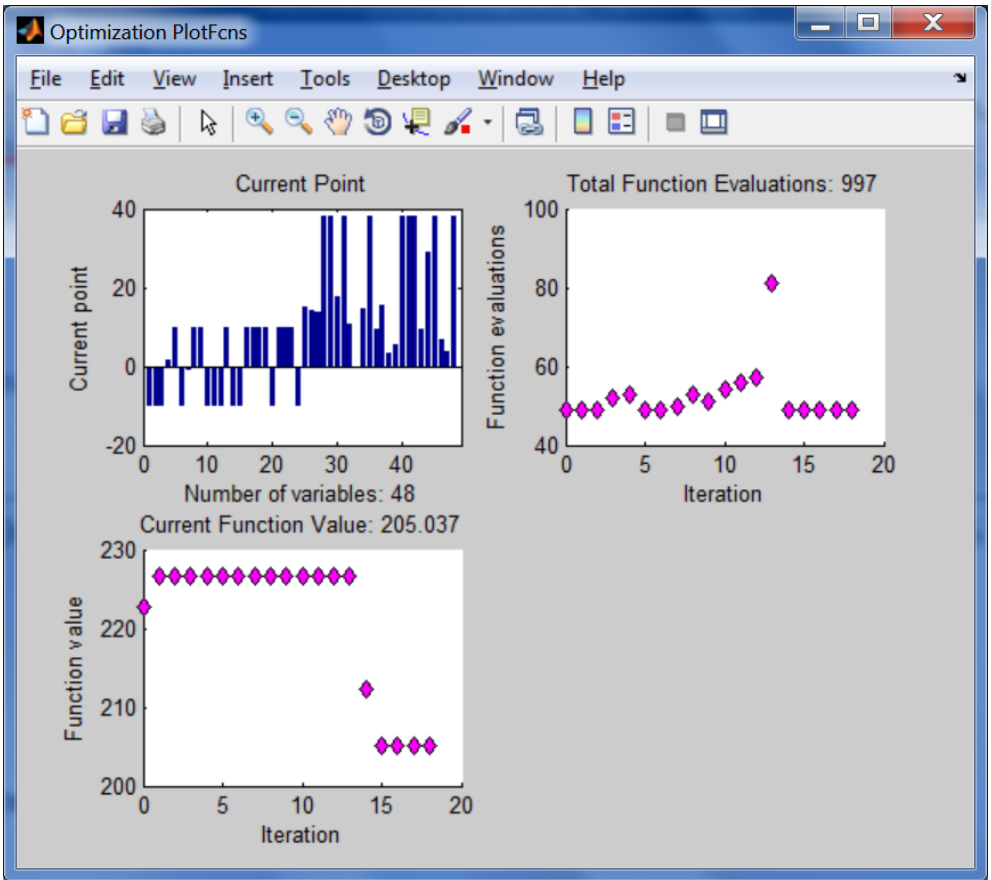

Fig. 5 Optimization results from "fmincon" solver. 


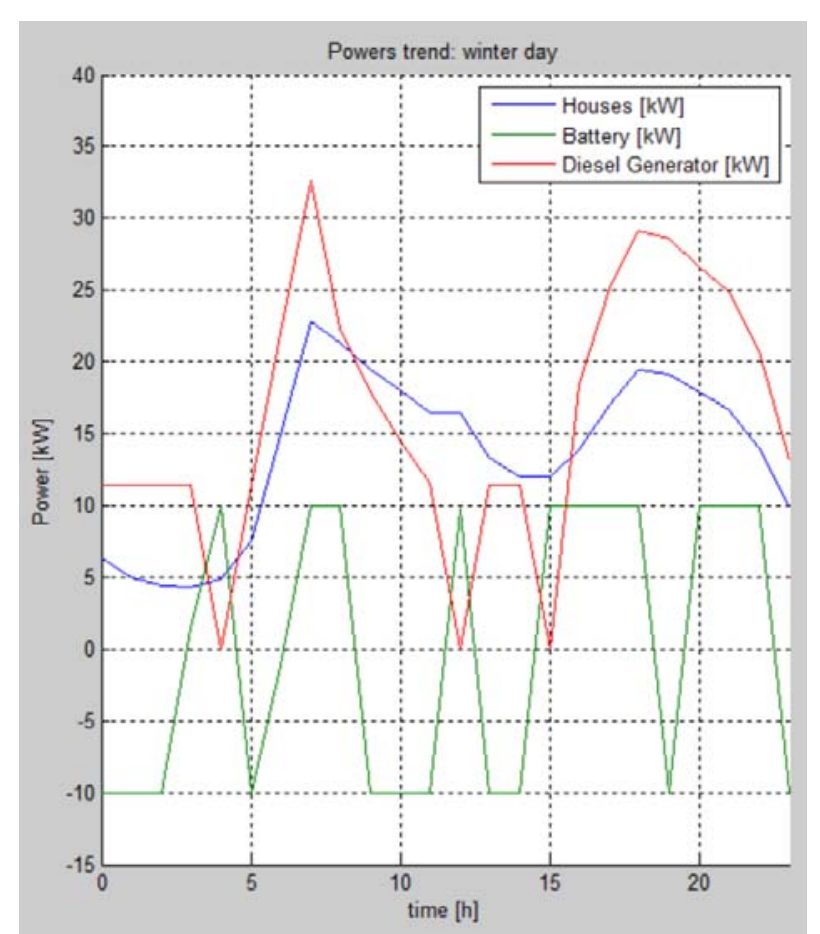

Fig. 6 Graphics of houses consumption, optimized Battery schedule and optimized Diesel generator schedule.

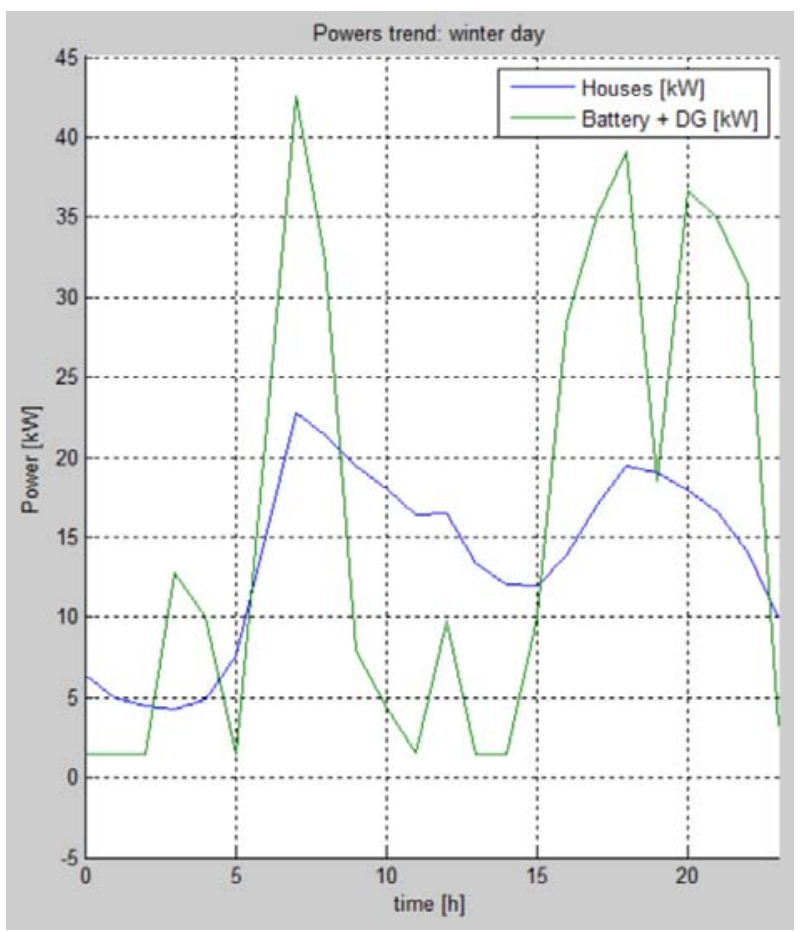

Fig. 7 Graphics of houses consumption, and of sum of Battery and Diesel generator energy.

of both: battery discharging and diesel generated energy are presented on Fig. 7 as a final comparison. The intervals, where the Load energy exceeds the sum of Battery + Diesel generator are covered by the energy generated by the photovoltaic system and by the wind turbine.

The connection of a battery system to the microgrid can provide benefits (absorbing energy when the production from RES is more than the consumption, and supplying energy to the main grid when the consumption is less than the produced by RES and stored by the battery energy). In case the microgrid operates in a grid connection mode, this may lead to economic benefits by selling energy to the main grid in case of surplus of production by the RES. This possibility can be taken into account and new optimization tasks could be formulated. This is one direction for further research activities. In the case considered here, the selling of energy to the main grid is impossible, because the experimental microgrid operates only in an isolated mode.

\section{Conclusion}

In this paper an optimization of a battery and diesel generator schedule in a microgrid is presented. Using the solution for the schedules two goals are achieved: 1) It is guaranteed that the load demand is covered by reserve high enough. 2) The optimization leads to $10.574 \%$ reduction of the costs. The result obtained shows, that by means of optimal battery and diesel generator schedules, a real safety margin concerning the system load is achieved. Additionally the costs for the end user are essentially reduced. Minimizing the objective function, the fuel consumption by the diesel generator is also minimized. In this way the harmful impact on the environment is reduced. The approach presented here is very promising and can be applied successfully, not only in rural regions, but also in big cities.

\section{Acknowledgement}

Authors recognize the valuable contribution to this study by the master degree student Donato Paoletta from the Universita degli Studi del Sannio di 
Benevento, Italy on Erasmus + mobility in TUS. This work is in the framework of CEEPUS network project № CIII-BG-1103-01-1617.

\section{References}

[1] Katiraei, F., Iravani, R., Hatziargyriou, N., and Dimeas, A. 2008. "Microgrids Management." IEEE Power Energy Mag. 6 (3): 54-65.

[2] Ahourai, F., and Faruque, M. A. A. 2013. Grid Impact Analysis of a Residential Microgrid under Various EV Penetration Rates in GridLAB-D. Technical Report, TR 13-08, July. http://cecs.uci.edu/files/2013/07/TR-13-08.pdf.

[3] Marinelli, M. 2014. "Testing of a Predictive Control Strategy for Balancing." IEEE Transactions on Sustainable Energy, http://www.google.bg/url?sa=t\&rct=j\&q=\&esrc=s\&sourc $\mathrm{e}=$ web\&cd=1\&ved=0ahUKEwjXls_wwtvLAhVGOJoKH VjiA1kQFggaMAA\&url=http\%3A\%2F\%2Forbit.dtu.dk $\% 2$ Ffedora $\% 2$ Fobjects\%2Forbit $\% 3$ A $128890 \% 2$ Fdatastre ams\%2Ffile_683a02a2-5202-4eac-9259-ba2ecafa $8246 \%$ 2Fcontent\&usg=AFQjCNFrhNV26Tp2Mw_bYwW13KP mhpJXAw\&sig2=yM3-vo2g_vyS-o7gKqsi3w\&bvm=bv. 117868183,d.bGs.

[4] Marinova, G., and Guliashki, V. 2016. "Economic Energy Scheduling of an Islanded Microgrid." In Proceedings of Papers of the LI International Scientific Conference on Information, Communication and Energy Systems and Technologies ICEST2016 (Editor Prof. Dr. Mitrovski, C.), June 28-30, 2016, Ohrid, Macedonia, vol. I, pp. 339-342.

[5] Jeong, J., Kim, T., and Ryu, K. R. 2015. "Iterative Replanning of Diesel Generator and Energy Storage System for Stable Operation of an Isolated Microgrid." International Journal of Computer and Information Engineering 2: 2.

[6] Xiao, J., Bai, L., Li, F., Liang, H., and Wang, C. 2014. "Sizing of Energy Storage and Diesel Generators in an Isolated Microgrid Using Discrete Fourier Transform (DFT)." IEEE Transactions on Sustainable Energy 5 (3).

[7] "GridLab-D." [Online]. Available at: http://www.gridlabd.org/.

[8] Faruque, M. A. A., and Ahourai, F. 2014. "GridMat:
Matlab Toolbox for GridLAB-D to Analyse Grid Impact and Validate Residential Microgrid Level Energy Management Algorithms." Presented at the IEEE PES Conference on Innovative Smart Grid Technologies (ISGT'14), Washington DC, USA. Available at: http://aicps.eng.uci.edu/papers/GridMat-ISGT-2014.pdf.

[9] "Matlab." [Online]. Available at: http://www.mathworks.com/products/matlab/.

[10] Chassin, D. P. 2014. "GridLAB-D: An Agent-Based Simulation Framework for Smart Grids." Journal of Applied Mathematics.

[11] "GridMat: A Matlab/Simulink Toolbox for GridLAB-D." [Online]. Available at: http://aicps.eng.uci.edu/research/ CPES/Tools/GridMat.htm.

[12] Luu, N. A. 2014. "Control and Management Strategies for a Microgrid." Ph.D. Thesis, Université de Grenoble, France, 18.12., https://tel.archives-ouvertes.fr/tel01144941/ document.

[13] Seryoatmojo, H., Elbaset, A., Syafaruddin, A., and Hiyama, T. 2010. "Genetic Algorithm based Optimal Sizing of PV-Diesel-Battery System, Considering CO2 Emission and Reliability." International Journal of Innovative Computing, Information and Control 6 (10): 1-09-0844, ISSN: 1349-1198.

[14] Diaf, S., Belhamelb, M., Haddadic, M., and Louchea, A. 2008. "Technical and Economic Assessment of Hybrid Photovoltaic Wind System with Battery Storage in Corsica Island." Energy Policy 36 (2): 743-54.

[15] Dufo-Lopez, R., and Bernal-Agustin, J. L. 2008. "MultiObjective Design of PV-Wind-Diesel-Hydrogen-Battery Systems." Accepted for publication in Renewable Energy http://www.sciencedirect.com/science/journal/09601481.

[16] Skarstein, O., and Ulhen, K. 1989. "Design Considerations with Respect to Long-Term Diesel Saving in Wind/Diesel Plants." Wind Engineering 13 (2): 72-87.

[17] Parisio, A., and Glielmo, L. 2011. "A Mixed Integer Linear Formulation for Microgrid Economic Scheduling." Presented at the Virtual Power Plants, Distributed Generation, Microgrids, Renewables and Storage (IEEE SmartGridComm), Brussels, http://luigiglielmo.eu/wp-content/ uploads/2013/06/4.pdf.

[18] Chang, G. W., Lu, H. J., and Su, H. J. 2013. "Short-term Distributed Energy Resource Scheduling for a DC Microgrid." Energy and Power Engineering 5: 15-21. 